\title{
Research on Quality Reliability of Rolling Bearings by Multi - Weight Method (Part II : Experiment)
}

\author{
Xintao Xia ${ }^{1, a}$, Xiangfeng Chen ${ }^{2, b^{*}}$, Bin $\operatorname{Liu}^{3, c}$ and Zhen Chang ${ }^{4, d}$ \\ (Mechatronical Engineering College, Henan University of Science and Technology, Luoyang \\ 471003, China) \\ aemail:xiaxt1957@163.com, bemail:black_xfc@163.com, \\ cemail:Ibin1992@foxmail.com, demail:zhenc1992@163.com
}

Keywords: Rolling bearing; Quality reliability; Influence factors; Simulation

\begin{abstract}
In this paper, under the condition of lack of information, aiming at the quality reliability model of rolling bearing, an experimental study was carried out. The vibration acceleration of 30204 taper bearings was simulated to study by computer. Simulation results showed that it was feasible to study rolling bearings quality reliability by using this model despite the lack of information and unknown data trends and probability distribution.
\end{abstract}

\section{Introduction}

Rolling bearing is an important component of mechanical equipment [1-3]. Quality of the bearing has a great influence on bearing performance and there is a very important relationship between its quality and the quality of its components [4-6]. Bearing quality is mainly affected by vibration acceleration and vibration speed [7]. In this section, bearing vibration acceleration as evaluation index illustrates the application of mechanical product quality to achieve reliability.

\section{Experimental Study and Data Analysis}

In the test case, the vibration acceleration of 30204 tapered roller bearings is the index of its quality. The number of test samples is 30 sets, namely $n=30$. There are many influence factors in the vibration acceleration of bearing. In this paper, the processing parameters of roller, inner ring and outer ring are mainly considered. Among them, the roller has eight factors, the inner ring has seven factors, the outer ring has five factors, namely $m=20$ [8-9]. For the convenience of research, the symbols used in the experimental study and the meanings of the expression are shown in Table 1.

Table 130204 roller bearing quality factors symbols and their meanings [ $\mu \mathrm{m}]$

\begin{tabular}{cccccc}
\hline Symbol & Meaning & Component & Symbol & Meaning & Component \\
\hline X1 & $D w$ & roller & X11 & inner raceway roundness & inner race \\
X2 & $\Delta 2 \Phi$ & roller & X12 & inner raceway waviness & inner race \\
X3 & convexity & roller & X13 & inner raceway roughness & inner race \\
X4 & roundness & roller & X14 & Sif (flange) & inner race \\
X5 & waviness & roller & X15 & roughness (flange) & outer race \\
X6 & roughness & roller & X16 & $\Delta 2 \alpha$ & outer race \\
X7 & Bases roughness & roller & X17 & Le & outer race \\
X8 & Spherical runout & roller & X18 & outer raceway roundness & outer race \\
X9 & $\Delta 2 \beta$ & inner race & X19 & outer raceway waviness & outer race \\
X10 & $\mathrm{Li}$ & inner race & X20 & outer raceway roughness & outer race \\
\hline
\end{tabular}


30 sets of 30204 tapered roller bearings were randomly selected at the site of production and processing. After the numbering, its vibration acceleration values were measured and data sequence is $X_{0}$.

$X_{0}=(46,47.7,47.7,47,48,47.7,48,47.7,47.7,46.7,47.7,44,46,46.7,48,45,47,45.3,45.7,45.3,47.3,48$, $47,47.3,47.3,47,47.3,46.7,44.6,47.3)$

Then measured bearings were demolished and influence factors on the quality of inner ring, outer ring and roller were also measured respectively. Lastly, recorded measured value of each influence factors on the quality. Seeing figure 1.

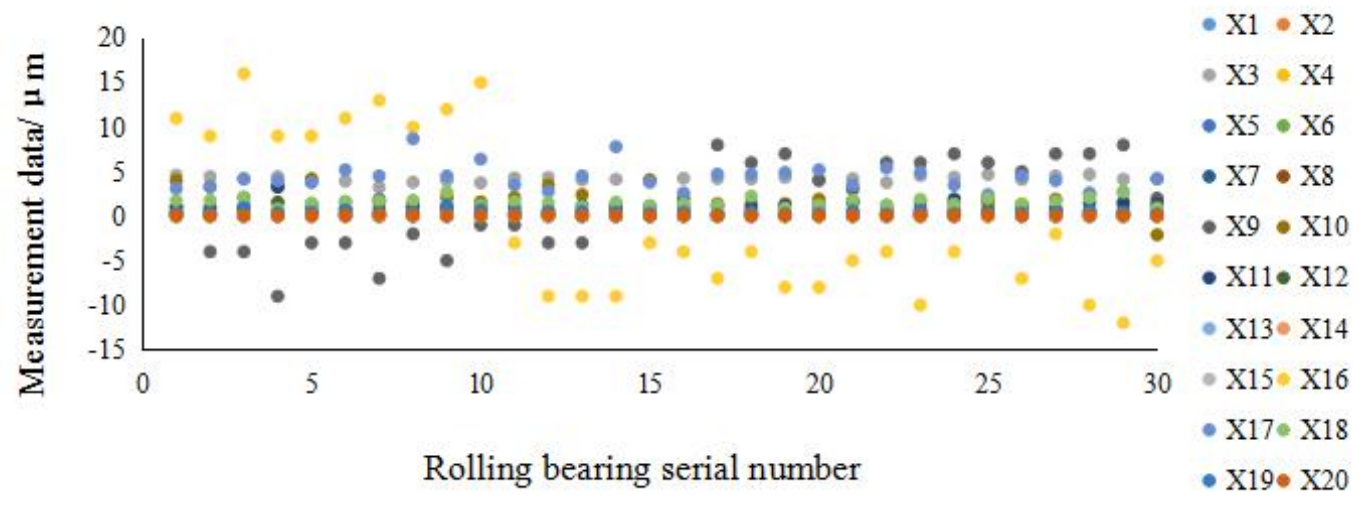

Fig. 1 The parameter data of each parameter

\section{Research on the Simulation Test of 30204 Tapered Roller Bearings}

Computer simulation is to simulate the experimental data through software, and then analyze the simulation data. This section is based on upper experimental study. The data of vibration acceleration and quality of tapered roller bearings is simulated and the reliability of its quality is study then. Through the computer simulation of vibration acceleration of the bearing, the 10000 simulated data of vibration acceleration is shown in figure 2 .

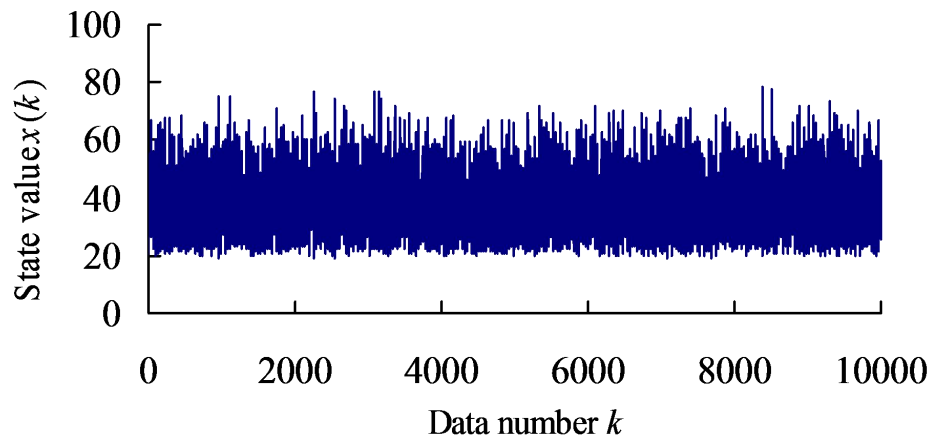

Fig. 230204 taper roller bearing simulation data of vibration acceleration

Similarly, the first 1000 data of each influencing factor of vibration acceleration were simulated by computer simulation test on 8 factors of roller, 7 factors of inner circle and 5 factors of outer circle. As a matter of space, only the first four figures are given as an example. 

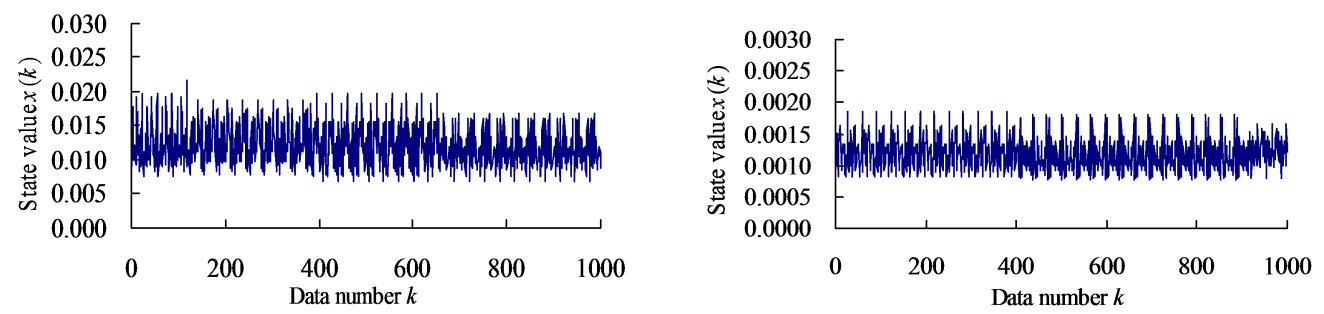

Fig. 3 Simulation data of roller diameter error Fig. 4 Simulation data of roller angle error
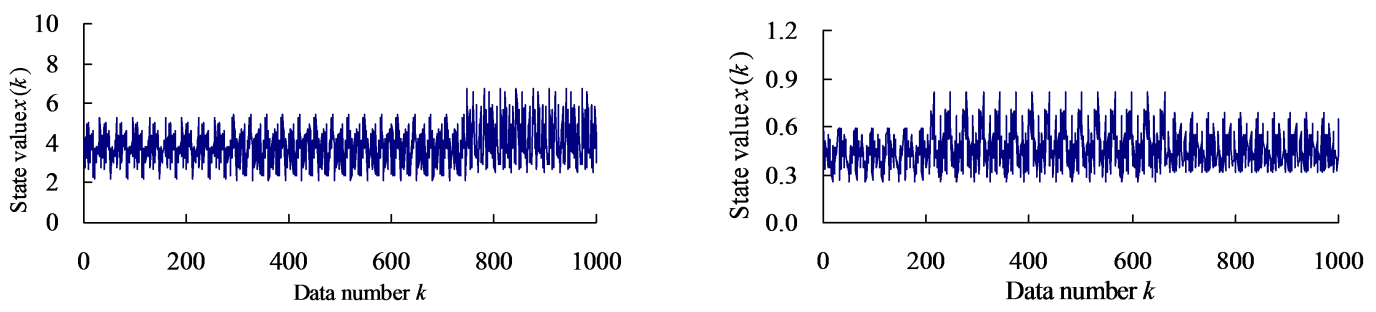

Fig. 5 Simulation data of roller convexity Fig. 6 Simulation data of roller roundness

Collate the simulation data of bearing vibration acceleration and influencing factors. From the simulation data diagram, data distribution status of bearing vibration acceleration and each influencing factor can be seen. According to [10], the quality grade of simulated data of vibration acceleration and each influencing factor is classified. Then frequency and frequency accumulation distribution of each influencing factor of vibration acceleration are got.

After quality grade of all simulation tests record data of bearing vibration acceleration and each influencing factor is classified, frequency accumulation distribution value of quality grade of each influencing factor of tapered roller bearing quality is collected. Then level synthesis matrix of each bearing influencing factor is got. The following is level synthesis matrix.

$\begin{array}{lcccccc} & \mathrm{P}_{1} & \mathrm{P}_{2} & \mathrm{P}_{3} & \mathrm{P}_{4} & \mathrm{P}_{5} & \mathrm{P}_{6} \\ \mathbf{X}_{1} & 0.3000 & 0.1649 & 0.5103 & 0.7412 & 0.8844 & 0.9695 \\ \mathbf{X}_{2} & 0.0000 & 0.2349 & 0.9043 & 1.0000 & 1.0000 & 1.0000 \\ \mathbf{X}_{3} & 0.3092 & 0.4179 & 0.5250 & 0.6112 & 0.8159 & 0.9258 \\ \mathbf{X}_{4} & 0.0046 & 0.6475 & 0.9985 & 1.0000 & 1.0000 & 1.0000 \\ \mathbf{X}_{5} & 0.0000 & 0.2778 & 0.8822 & 0.9991 & 1.0000 & 1.0000 \\ \mathbf{X}_{6} & 0.0000 & 0.0000 & 0.2299 & 0.9761 & 1.0000 & 1.0000 \\ \mathbf{X}_{7} & 0.0516 & 0.2479 & 0.5586 & 0.8310 & 1.0000 & 1.0000 \\ \mathbf{X}_{8} & 0.0000 & 0.0229 & 0.0982 & 0.2315 & 0.5101 & 0.9034 \\ \mathbf{X}_{9} & 0.0000 & 0.0181 & 0.2073 & 0.7552 & 0.9457 & 1.0000 \\ \mathbf{X}_{10} & 0.0000 & 0.0000 & 0.6351 & 0.9688 & 1.0000 & 1.0000 \\ \mathbf{X}_{11} & 0.0000 & 0.0201 & 0.3462 & 0.9379 & 1.0000 & 1.0000 \\ \mathbf{X}_{12} & 0.0000 & 0.0920 & 0.6886 & 0.9964 & 1.0000 & 1.0000 \\ \mathbf{X}_{13} & 0.0000 & 0.0297 & 0.1753 & 0.7693 & 0.9947 & 1.0000 \\ \mathbf{X}_{14} & 0.0000 & 0.0640 & 0.3326 & 0.6619 & 0.8652 & 0.9821 \\ \mathbf{X}_{15} & 0.0000 & 0.0000 & 0.0687 & 0.6169 & 0.8972 & 1.0000 \\ \mathbf{X}_{16} & 0.0000 & 0.0000 & 0.0410 & 0.2406 & 0.6323 & 0.8861 \\ \mathbf{X}_{17} & 0.0000 & 0.0000 & 0.5279 & 0.9620 & 1.0000 & 1.0000 \\ \mathbf{X}_{18} & 0.0000 & 0.0000 & 0.1210 & 0.6372 & 0.9883 & 1.0000 \\ \mathbf{X}_{19} & 0.0000 & 0.0330 & 0.4950 & 0.9527 & 1.0000 & 1.0000 \\ \mathbf{X}_{20} & 0.0000 & 0.2368 & 0.8350 & 0.9929 & 1.0000 & 1.0000\end{array}$


According to the determination method of influencing factor weight and the calculating method of weight of influencing factors based on mean constant sequence for reference sequence in Gray relational weighting method, weight value of data sequence of each influencing factor and vibration acceleration performance of tapered roller bearings can be calculated. The following is the weight of each influencing factor.

$$
\begin{aligned}
& \omega_{1}^{5}=0.3031, \quad \omega_{2}^{5}=0.0566, \quad \omega_{3}^{5}=0.5674, \quad \omega_{4}^{5}=0.3441, \quad \omega_{5}^{5}=0.3262, \quad \omega_{6}^{5}=0.3070, \\
& \omega_{7}^{5}=0.3146, \quad \omega_{8}^{5}=0.1882, \quad \omega_{9}^{5}=0.5021, \quad \omega_{10}^{5}=0.4465, \quad \omega_{11}^{5}=0.3654, \quad \omega_{12}^{5}=0.3287, \\
& \omega_{13}^{5}=0.3087, \quad \omega_{14}^{5}=0.1126, \quad \omega_{15}^{5}=0.3311, \quad \omega_{16}^{5}=0.7533, \quad \omega_{17}^{5}=0.4559, \quad \omega_{18}^{5}=0.4111 \text {, } \\
& \omega_{19}^{5}=0.3367, \quad \omega_{20}^{5}=0.3081
\end{aligned}
$$

According to weight value of influence factor and quality grade, accumulation distribution matrix can be implemented. According to the method of factor decomposition and synthesis, state composition of influence factors of quality grade is got.

$$
x_{1}=0.0402, \quad x_{2}=0.1193, x_{3}=0.4245, x_{4}=0.7654, x_{5}=0.9163, x_{6}=0.9777
$$

Similarly, according to other determination methods of influencing factors weight, state synthesis value of influencing factors of different weighting methods are got. State value of influencing factor of each quality grade composes synthesis value matrix. Thus, the following is the synthesis value matrix.

$\begin{array}{cccccc}x_{1} & x_{2} & x_{3} & x_{4} & x_{5} & x_{6} \\ \omega_{l}^{1} 0.0319 & 0.1302 & 0.4707 & 0.7744 & 0.9264 & 0.9835 \\ \omega_{l}^{2} 0.0324 & 0.1210 & 0.4438 & 0.7723 & 0.9163 & 0.9799 \\ \omega_{l}^{3} 0.0321 & 0.1265 & 0.4600 & 0.7863 & 0.9224 & 0.9820 \\ \omega_{l}^{4} 0.0421 & 0.0858 & 0.3595 & 0.6149 & 0.9108 & 0.9660 \\ \omega_{l}^{5} 0.0334 & 0.1249 & 0.4569 & 0.7913 & 0.9253 & 0.9828\end{array}$

According to organization reliability theory, the influence coefficient $a=10$ and $b=2.2$ are selected. The matrix of synthetic state value of influencing factors can be used to obtain the reliability matrix of vibration acceleration of tapered roller bearing at different quality grades.

$\begin{array}{cccccc} & \omega_{l}^{1} & \omega_{l}^{2} & \omega_{l}^{3} & \omega_{l}^{4} & \omega_{l}^{5} \\ r_{1}(k) & 0.00510 & 0.00528 & 0.00517 & 0.00563 & 0.00847 \\ r_{2}(k) & 0.10656 & 0.09149 & 0.10041 & 0.09779 & 0.08885 \\ r_{3}(k) & 0.85133 & 0.81262 & 0.83659 & 0.83221 & 0.78085 \\ r_{4}(k) & 0.99759 & 0.99664 & 99724 & 0.99746 & 0.99613 \\ r_{5}(k) & 0.99979 & 0.99974 & 0.99977 & 0.99978 & 0.99974 \\ r_{6}(k) & 0.99993 & 0.99993 & 0.99993 & 0.99993 & 0.99993\end{array}$

From the Eq.31, taking B $=100$ 000, Self-resampling of each quality grade in the reliability data matrix was performed by computer simulation. Then the true value of each bearing quality grade are obtained from the Eq.37, and the true reliability figure of simulation test bearing are also obtained. As shown in Figures 7.

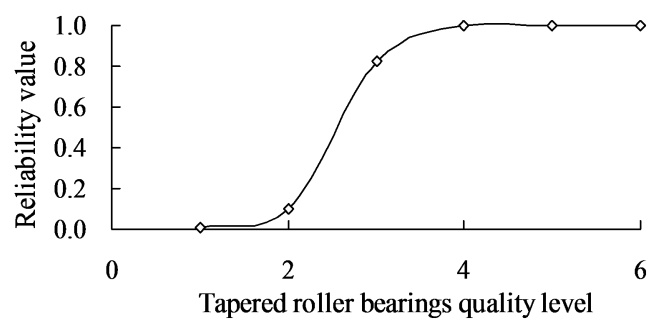

Fig. 7 True values estimation of simulation test tapered roller bearing simulation test achieving reliability 
The true value estimation figure of simulation test bearing shows that the test results obtained under a small amount of information are more reliable. The change trend of vibration acceleration of roller bearing is the same. That is, with the improvement of quality grade, its quality reliability is gradually reduced, at higher quality levels when the change is more obvious. In addition, simulation results show that the reliability of the tapered roller bearings can reach $99.72 \%$ when the vibration acceleration grade of the bearings is in the fourth grade.

\section{Summary}

In this paper, Taking the 30204 tapered roller bearing as an example, the reliability model of rolling bearing quality is established and the computer simulation test is carried out. Then, based on the poor information theory, the reliability of the rolling bearing quality is estimated by the true value. The simulation results show that the reliability model of rolling bearing quality and the method of true value estimation of reliability are effective and feasible in the condition of less data and small sample.

\section{Acknowledgements}

This project is supported by National Natural Science Foundation of China (Grant Nos. 51475144).

\section{References}

[1] P. Miao, D. Zheng and Y.S. Wang: Harbin Bearing, Vol. 29 (2008) No.2, p38.(In Chinese)

[2] X.T. Xia, W. Ma and T.C. Jie: Rolling Bearing Manufacturing Technology(Mechanical Industry Press, China 2007), p.2.(In Chinese)

[3] J.E. Ban, B.H. Rho and K.W. Kim: Tribology International, Vol. 40 (2007) No.1, p21.

[4] B.H. Rho, D.G. Kim and K.W. Kim: Tribology Transactions, Vol. 48 (2005) No.2, p238-244.

[5] J.S. Nam, H.E. Kim and K.U. Kim: Journal of Mechanical Science and Technolugy, Vol.27 (2013)No.6, p1801.

[6] X.T. Xia, Z.Y. Wang and H. Chang: Journal of Aerospace Power, Vol. 20 (2005) No.2, p250.(In Chinese)

[7] M. Kenneth L: Proceedings of the 1994 International Mechanical Engineering Congress and Exposition(Chicago, IL, USA, November 6-11, 1994). Vol. 8. p.153.

[8] T. Constantine M., S. Luz and V. Anthony A.: ASME 2016 Joint Rail Conference (Columbia, SC,USA, APR 12-15, 2016).

[9] J. Martin, C. Ladislav and S. Zdenek: 15th International Symposium on Metallography (Stara Lesna, SLOVAKIA, APR 24-26, 2013). Vol. 782. p.247.

[10] Y.T. Shang: Study on Assessment Methods of Rolling Bearing Quality Based on Poor Information(MS., Henan University of Science and Technology, China, 2014), p.61. 